\title{
ARticulações entre os ObJetivos de Desenvolvimento Sustentável E A EdUCAÇÃo CTS NO CONTEXTO ESCOLAR
}

\author{
ARTICULATIONS BETWEEN SUSTAINABLE DEVELOPMENT GOALS AND STS EDUCATION \\ IN THE SCHOOL CONTEXT
}

ARTICULACIONES ENTRE OBJETIVOS DE DESARROLLO SOSTENIBLE Y EDUCACIÓN CTS EN EL CONTEXTO ESCOLAR

\section{Vanessa Candito \\ (iD)}

Mestra em Educação em Ciência pela Universidade Federal do Rio Grande do Sul (UFRGS)

vanecandito@gmail.com

\section{Karla Mendonça Menezes (iD) 9}

Doutora em Educação em Ciências pela Universidade Federal de Santa Maria (UFSM)

karlam.ef@gmail.com

\section{Carolina Braz Carlan Rodrigues (iD) 9}

Doutora em Educação em Ciências: Química da Vida e Saúde pela Universidade Federal de Santa Maria (UFSM) carolinabcarlan@gmail.com

\section{Leonan Guerra}

\section{iD 9}

Mestre em Educação em Ciências pela Universidade Federal de Santa Maria (UFSM)

Doutorando no PPG em Educação em Ciências: Química da Vida e Saúde pela Universidade Federal do Rio Grande do Sul (UFRGS) leonan.guerra@yahoo.com.br

\begin{abstract}
Resumo
Esse estudo analisou como os Objetivos de Desenvolvimento Sustentável (ODS) se articulam à Educação CTS e se inserem nas práticas pedagógicas de docentes. Caracteriza-se como uma pesquisa quanti-qualitativa, de caráter exploratório e descritivo, foi realizada com professores do Ensino Fundamental e Médio, que participaram de um processo formativo conduzido por oficinas pedagógicas, orientados pela Educação CTS articulados aos ODS. Após o processo formativo, os docentes responderam uma questão sobre os ODS, e foi realizada uma ação dialógica onde relataram a abordagem dos ODS nas suas práticas. Uma formação docente voltada para o pensamento crítico, reflexivo e sustentável, integra os esforços para o alcance dos ODS. Assim, formações continuadas por meio a educação CTS articulada aos ODS, apontam caminhos para uma educação que envolva os professores em uma nova forma de ver, pensar e desenvolver suas práticas pedagógicas, para uma formação integral dos escolares com um pensamento orientado para o futuro.
\end{abstract}

Palavras-chave: Ciência-Tecnologia-Sociedade. Formação docente. Práticas docentes.

Recebido em: 16 de março de 2021. Aprovado em: 31 de agosto de 2021.

Como citar esse artigo (ABNT):

CANDITO, Vanessa et al. Articulações entre os Objetivos de Desenvolvimento Sustentável e a Educação CTS no contexto escolar. Revista Prática Docente, v. 6, n. 2, e058, 2021. http://doi.org/10.23926/RPD.2021.v6.n2.e058.id1050 


\section{Abstract}

This study analyzed how the Sustainable Development Goals (SDGs) are linked to STS Education and are inserted in the pedagogical practices of teachers. It is characterized as a quantitative-qualitative, exploratory and descriptive research, carried out with elementary and high school teachers, who participated in a training process conducted by pedagogical workshops, guided by STS Education articulated with the SDGs. After the training process, the professors answered a question about the SDGs, and a dialogic action was carried out in which they reported the approach of the SDGs in their practices. Teacher training focused on critical, reflective, and sustainable thinking is part of the efforts to achieve the SDGs. Thus, continuing education through STS education articulated with the SDGs points out paths for an education that involves teachers in a new way of seeing, thinking, and developing their pedagogical practices, for a comprehensive education of students with futureoriented thinking.

Keywords: Science-Technology-Society. Teacher training. Teaching practices.

\section{Resumen}

Este estudio analizó cómo los Objetivos de Desarrollo Sostenible (ODS) se vinculan a la Educación CTS y se insertan en las prácticas pedagógicas de los docentes. Se caracteriza por ser una investigación cuantitativa-cualitativa, exploratoria y descriptiva, realizada con docentes de primaria y secundaria, quienes participaron de un proceso de formación realizado por talleres pedagógicos, guiados por Educación CTS articulada con los ODS. Luego del proceso de capacitación, los profesores respondieron una pregunta sobre los ODS, y se llevó a cabo una acción dialógica en la que informaron el enfoque de los ODS en sus prácticas. Una formación docente centrada en el pensamiento crítico, reflexivo y sostenible es parte de los esfuerzos para alcanzar los ODS. Así, la educación continua a través de la educación CTS articulada con los ODS, señalan caminos para una educación que involucre a los docentes en una nueva forma de ver, pensar y desarrollar sus prácticas pedagógicas, para una educación integral de los estudiantes con un pensamiento orientado al futuro.

Palabras clave: Ciencia-Tecnología-Sociedad. Formación docente. Prácticas docentes. 


\section{INTRODUÇÃo}

As mudanças no plano socioeconômico e cultural, resultantes do processo de globalização capitalista, vêm interferindo substancialmente na estrutura e dinâmica das sociedades. Bigliard e Cruz (2007) apontam que a sociedade atual, caracterizada pelo modo de vida capitalista e consumista, trata os recursos naturais como fonte de matéria-prima para seu consumo; além de entender o ambiente natural como um depósito para seus resíduos, desconsiderando que o homem é parte integrante da natureza e que tudo a sua volta compõe-se de recursos naturais finitos. Neste sentido, torna-se necessária a estruturação e aplicação de políticas públicas que possam mitigar os conflitos socioambientais, visando a ampliação da compreensão sobre os fenômenos naturais e sobre o seu processo de desenvolvimento.

A educação científica, por meio da perspectiva Ciência-Tecnologia-Sociedade (CTS), pode constituir-se como alicerce para a construção de um novo modo de desenvolvimento sustentável e como oportunidade de formação científica para os cidadãos. Em conformidade, para Bazzo e Colombo (2001), a educação CTS possui uma natureza interdisciplinar, e possui como proposta realizar estudos voltados à ciência e tecnologia e suas interações e implicações à sociedade.

Conforme Pinheiro (2005), esse movimento não teve origem no contexto educacional, mas vem ganhando espaço na educação, visto que a escola é um ambiente favorável para o desenvolvimento humano. Em vista disso, a educação CTS colabora para que os educandos efetivamente exerçam a cidadania, tornando-se qualificados para tomada de decisões (SANTOS; MORTIMER, 2002). Assim, o ensino em uma perspectiva CTS propicia o desenvolvimento da capacidade crítica do estudante, ao ponto de permitir uma nova leitura de mundo, mediante a uma prática reflexiva. Com isso, o conhecimento é construído e reconstruído diante das situações ou questões-problemas; os conceitos científicos vão sendo apropriados à medida que o conhecimento e o conceito anterior já não satisfazem a resolução das problemáticas levantadas (SOUZA; ALMEIDA, 2020).

Destarte, educar para a sustentabilidade envolve a promoção do pensamento crítico e responsável, sobretudo, a habilidade de converter esse pensamento em ações que possam transformar a realidade, tanto nas esferas locais, quanto globais. Corroborando com Santos e Schnetzler (2015), que se referem à cidadania como a participação dos sujeitos na sociedade, ressalta-se que para o cidadão efetivar sua participação é imperioso que ele disponha de 
subsídios que estão diretamente vinculados aos problemas sociais que comprometem o cidadão, os quais exigem um posicionamento quanto ao encaminhamento de suas soluções.

A Base Nacional Comum Curricular (BNCC) ao definir suas competências para resolver demandas complexas da vida cotidiana, do pleno exercício da cidadania e do mundo do trabalho, reconhece que a educação necessita assegurar valores e instigar ações que colaborem para a mudança da sociedade, tornando-a mais humana, socialmente justa e voltada à preservação da natureza. Nesse sentido, se manifesta alinhada à Agenda 2030 da Organização das Nações Unidas (BRASIL, 2017).

Desse modo, percebe-se que a educação científica por meio da perspectiva CTS, aliada às temáticas para a construção de um desenvolvimento sustentável, é instrumento indispensável para formar uma sociedade crítica, reflexiva e preocupada com o seu papel e suas responsabilidades individuais e coletivas como cidadãos. Assim, a adição de questões relevantes, vinculadas ao mundo vivenciado pelos estudantes e à educação CTS de cunho socioambiental é considerada primordial para uma educação de qualidade, que busque promover a apropriação de valores e atitudes transformadoras. Nesse processo, a formação contínua docente se faz necessária, pois busca-se, por meio dela, além da qualificação profissional, uma formação que considere o docente como sujeito do processo, favorecendo sua prática (RODRIGUES, C. B. C. et al., 2020). Dessa forma, associar a Agenda 2030 à educação CTS, a partir do estudo dos Objetivos de Desenvolvimento Sustentável (ODS), torna-se importante a fim de potencializar as ações formativas dos docentes.

Esse estudo se propõe a analisar como os Objetivos de Desenvolvimento Sustentável se articulam à Educação CTS e se inserem nas práticas pedagógicas de docentes de uma escola pública estadual localizada no município de Santa Maria-RS.

\section{A AGENDA 2030 E O ENFOQUE CTS NA FORMAÇÃO DE PROFESSORES}

Com o intuito de propor uma discussão que sinalizasse os grandes problemas do planeta, a Organização das Nações Unidas (ONU) lançou em 2015 a Agenda 2030. Esse documento apresenta os Objetivos de Desenvolvimento Sustentável, os quais representam a oportunidade de promover ações globais para fortalecer a cultura da sustentabilidade ambiental e social.

A agenda conta com 17 ODS, sendo eles: 
Figura 1 - ODS propostos pela Agenda 2030 da ONU

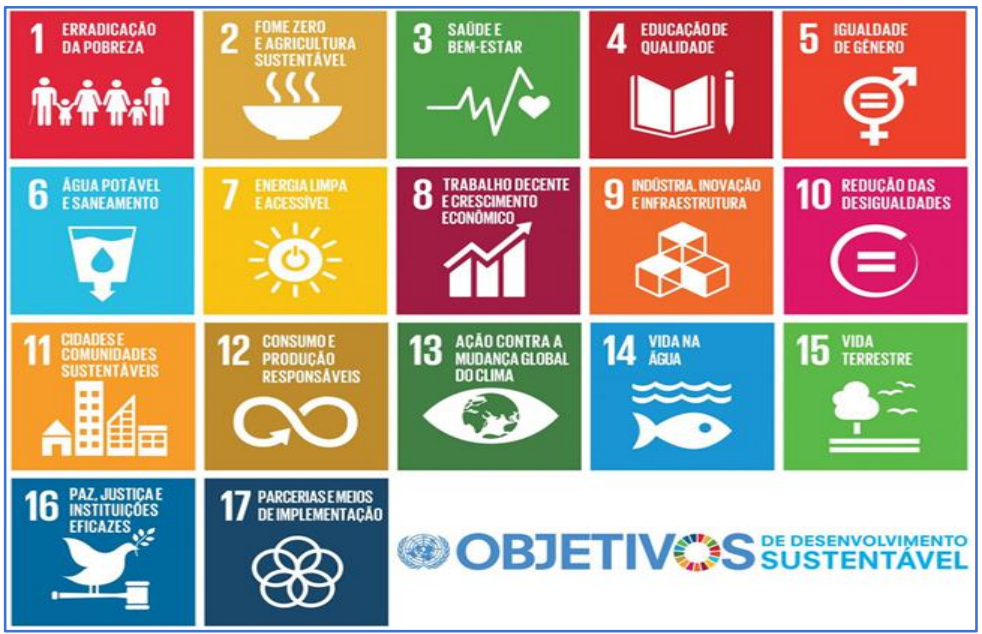

Fonte: Site da Organização das Nações Unidas ${ }^{1}$.

Os ODS são transversais e indivisíveis. Logo, são abordados de forma sistêmica e interdisciplinar. Ao propor estratégias diversificadas para atingir as metas, visam melhorar as relações entre os sujeitos, e entre eles com o mundo. Não obstante, a educação será o caminho mais eficaz na promoção dos ODS entre as pessoas, pois é um instrumento de emancipação e de empoderamento da sociedade, com vistas a promover oportunidades de aprendizagem ao longo da vida para todos.

Assim, a Educação para o Desenvolvimento Sustentável (EDS) visa desenvolver competências que capacitem as crianças, jovens e adultos a refletir sobre as próprias ações, levando em conta os impactos sociais, culturais, econômicos e ambientais, atuais e futuros, a partir de uma perspectiva local e global. Formar indivíduos críticos para agir em situações complexas de forma sustentável pode levá-los a adotar novas direções, como participar em processos sociopolíticos, movimentando suas sociedades rumo ao desenvolvimento sustentável (ONU, 2017).

A Agenda 2030 para o Desenvolvimento Sustentável reflete a importância de uma resposta educacional adequada, isso porque a educação aparece explicitamente formulada no Objetivo 4: "Assegurar a educação inclusiva e equitativa e de qualidade, e promover oportunidades de aprendizagem ao longo da vida para todos" (ONU, 2017, online). Nesse sentido, como os temas propostos pelos ODS são interdisciplinares e transversais podem ser trabalhados em diferentes componentes curriculares, tanto de forma isolada, quanto conjunta,

\footnotetext{
${ }^{1}$ Disponível em: https://nacoesunidas.org/pos2016/agenda2030/. Acesso em: 01 de mar. 2021.
} 
o que possibilita a concretização de projetos educativos que podem envolver diversas áreas do conhecimento e faixas etárias.

Nesse contexto, Santos e Mortimer (2002) ressaltam que a abordagem curricular com ênfase em CTS capacita os estudantes à análise crítica dos impactos causados pela ciência e tecnologia em movimento com as questões socioambientais. Em vista disso, a educação com enfoque CTS pode colaborar para a execução e sucesso do Objetivo 4, pois, assim, possibilitará que os sujeitos exercitem a cidadania, formando-se qualificados para tomadas de decisões responsáveis no contexto da sociedade em que vivem.

Para tanto, é preciso refletir sobre os cursos de formação continuada de professores, já que são os educadores que mediam os saberes e proporcionam o ensino aos estudantes. Segundo Zeichner (2008), para que o ensino possa voltar-se à formação do cidadão crítico e autônomo, sendo mais democrático e centrado no estudante, é indispensável que os educadores vivenciem os processos de sua própria formação nessa mesma perspectiva. Nesse seguimento, a educação CTS pode ser entendida como um fundamento da prática pedagógica, pois relaciona questões científicas, tecnológicas e sociais, e traz discussões para a sala de aula, sobre as implicações sociais e éticas referentes ao uso da Ciência e da Tecnologia (RODRÍGUEZ; DEL PINO, 2017). E nesse viés, Nóvoa (2009) ressalta que a formação docente deve partir do trabalho em equipe e do exercício coletivo da profissão, reforçando a importância da intervenção conjunta nos projetos educativos da escola.

Partindo do pressuposto que o significativo ensino deve objetivar a aprendizagem dos estudantes com vistas à alfabetização científica, acredita-se que a educação CTS articula-se com os ODS na viabilização, por meio de práticas pedagógicas diversificadas, do exercício à cidadania e de uma formação de sujeitos críticos, responsáveis eticamente e autônomos.

\section{Procedimentos Metodológicos}

Esse estudo contempla os aspectos de uma pesquisa quanti-qualitativa, de caráter exploratório e descritivo, conforme Gil (2008). Foi realizado em uma Escola Pública Estadual (Escola Estadual de Ensino Médio Marechal Humberto de Alencar Castelo Branco), localizada no município de Santa Maria/RS, onde participaram da pesquisa 20 professores, de diferentes áreas do conhecimento, que atuam no Ensino Fundamental e/ou no Ensino Médio.

Assim, fizeram parte de um processo formativo conduzido por oficinas pedagógicas, compostas de quatro encontros presenciais na sede da escola, orientadas pela educação CTS, na qual muitos momentos foram articulados por meio das inter-relações CTS em diversos 
contextos, envolvendo os ODS da Agenda 2030 da Organização das Nações Unidas (ONU). Cabe salientar que o processo formativo foi aberto à participação de todo o corpo docente (23 professores), porém, como alguns docentes conciliavam atividades em outras instituições de ensino, não foram todos que puderam participar de todos os encontros.

Após o processo formativo, os docentes responderam individualmente a um questionamento: "Durante este ano [2019], suas atividades foram atribuídas por meio de quais Objetivos do Desenvolvimento Sustentável?’. Em continuidade, foi realizada uma ação dialógica onde os professores relataram a abordagem dos ODS nas suas práticas pedagógicas. Dessa forma, como coleta de dados, também foram utilizadas anotações em diário de campo e observação participante.

Todas as informações coletadas foram examinadas por meio da Análise de Conteúdo de Bardin (2016). As informações constantes nos questionários foram transcritas em planilha Excel, e os resultados foram apresentados em valores percentuais e organizados graficamente. A identificação dos participantes foi preservada, por isso, está organizada por meio dos caracteres: P1, P2, P3, [...], P20. Os procedimentos éticos instituídos para esse tipo de estudo foram respeitados e aprovados pelo Comitê de Ética da Universidade vinculada aos autores, sob o número CAAE: 13846619.2.0000.5346. Além disso, os participantes assinaram o Termo de Consentimento Livre e Esclarecido (TCLE).

\section{Resultados E Discussões}

Tendo como prerrogativa que os Objetivos de Desenvolvimento Sustentável estão interligados, os achados dessa pesquisa permitiram identificar quais os ODS perpassam as práticas pedagógicas dos docentes investigados, e esses resultados estão apresentados na Figura 2. Cabe salientar que os ODS não contemplados na Figura 2 não foram referidos pelos docentes participantes da pesquisa. 
Figura 2 - ODS abordados nas práticas pedagógicas

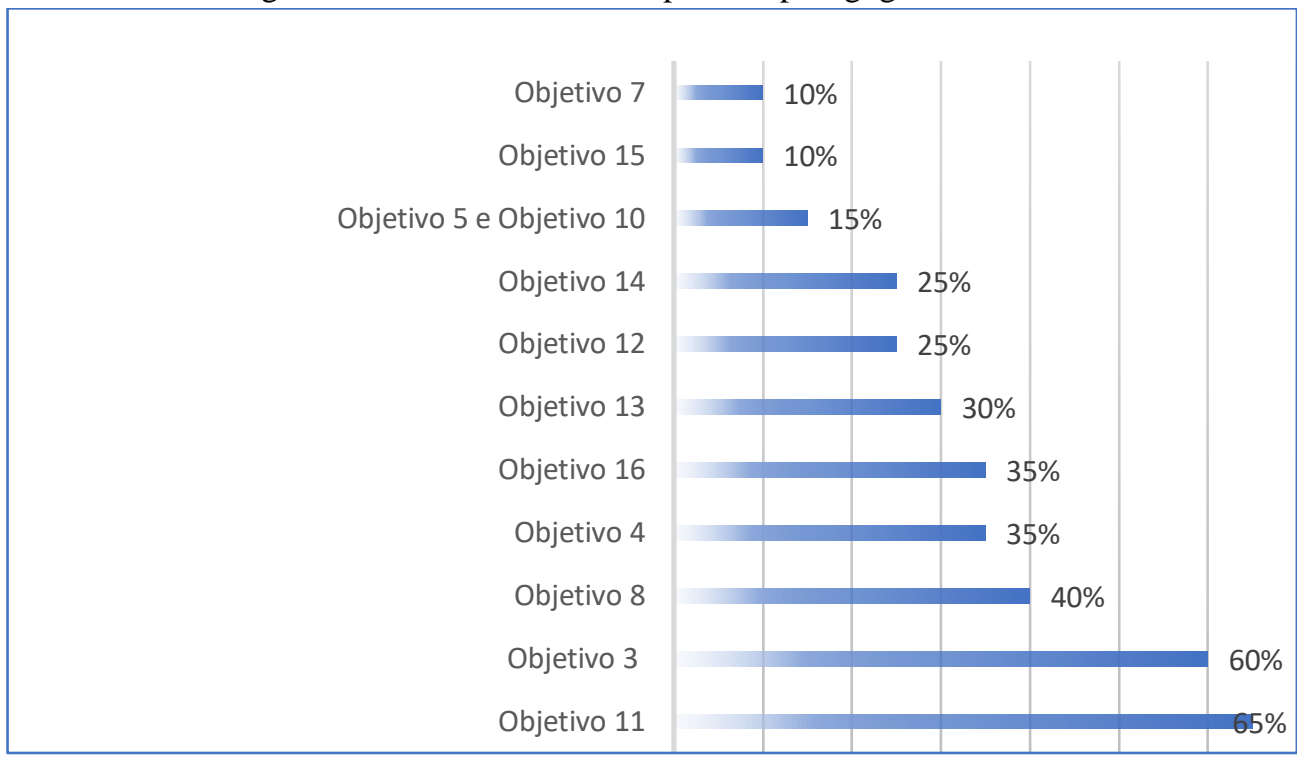

Fonte: Dados da pesquisa (2021).

Nota: valores percentuais são representativos ao número total de professores participantes no processo formativo

Ao analisar os resultados, evidencia-se que a abordagem do Objetivo 4 - Educação de Qualidade: Assegurar a educação inclusiva e equitativa de qualidade, e promover oportunidades de aprendizagem ao longo da vida para todos, teve referência de 35\% dos professores. Nesse sentido, a educação é tanto um objetivo em si, como um meio para atingir todos os outros ODS, sendo fundamental para o desenvolvimento sustentável (UNESCO, 2017). Do ponto de vista da práxis pedagógica dialógica crítica, levar a proposta de implementação do ODS4 para a sala de aula, nos diferentes níveis de ensino, poderá auxiliar diretamente na compreensão e consolidação de uma prática que, por ser pautada na dialogicidade, evitará o exercício de uma educação bancária (RAMINELI; ARAÚJO, 2019)

Para Paulo Freire (2010), a concepção de ensinar "[...] não é transferir conhecimentos, mas criar as possibilidades para a sua própria produção ou a sua construção" (FREIRE, 2010, p. 47). Nessa perspectiva, o ensino dos ODS deverá acontecer com os educandos e não para eles, ou seja, essa prática deverá ser realizada em diálogo entre os sujeitos. Sabendo que uma prática educativa deve ser crítica e conscientizadora, assim partir da realidade dos educandos, é o ponto de partida a ser investigado. De tal modo, compreender essa realidade permitirá uma maior percepção de seus aspectos e o desenvolvimento de uma nova visão ambiental, que poderá promover a análise crítica e possibilitar a intervenção com potencial de transformação.

Ao analisar os assuntos abordados por alguns professores, ressalta-se a fala de uma das docentes que permite interligar o ODS 5 - Alcançar a igualdade de gênero e empoderar todas 
as mulheres e meninas - ao ODS 10 - Reduzir a desigualdade dentro dos países e entre eles -, conforme observado na Figura 2, acima. O excerto a seguir demonstra como a professora abordou esses temas: "Trabalhei com os estudantes a história afro-brasileira. Assim obtive um resultado positivo com esse tema, e os educandos se interessaram muito" (P10). Nesse sentido, o trabalho escolar, balizado em propostas que atentem a todas as formas de discriminação de gênero, nas suas intersecções com raça, etnia, idade, deficiência, orientação sexual, cultura, religião e nacionalidade, deve ter espaço nas práticas pedagógicas a partir de um ambiente escolar de cooperação e reflexão quanto aos valores e atitudes a serem construídos.

Segundo a docente P8: “[...] incentivar o reaproveitamento da água e de embalagens, produzir uma horta orgânica, para os alimentos serem utilizados na merenda escolar [...]”, relaciona-se ao ODS 3 - Assegurar uma vida saudável e promover o bem-estar para todas e todos, em todas as idades. No contexto escolar, a educação compreende o ensino e a aprendizagem de temas, desenvolvidos de forma sistematizada e integrados ao currículo escolar, relacionados à saúde (MOHR, 2002). Inseridas nessa perspectiva, as práticas docentes abordaram a saúde dos escolares, sua alimentação, a produção de alimentos orgânicos, assim como a possível realização de uma horta orgânica na escola. É importante resgatar, conforme descrito por Menezes et al. (2020), que diferentes projetos foram desenvolvidos pela instituição de P8, os quais adotaram como temática central a promoção da saúde e envolveram um programa de intervenções colaborativas no ambiente escolar utilizando a metodologia de aprendizagem por projetos. Além disso, foram oportunizados processos formativos contínuos aos docentes e discentes da escola.

Na descrição da P7 menciona-se que é "[...] importante utilizar a energia solar [...]" e “[...] desenvolver e aplicar novas tecnologias na produção”. Assim, ressalta-se a importância de utilizar a energia solar como meio de sustentabilidade. Desse modo, é possível relacionar o fragmento da docente ao ODS 7 - Assegurar o acesso confiável, sustentável, moderno e a preço acessível à energia para todos. Segundo a ONU (2017), a energia limpa significa menos poluição, e os investimentos em energias renováveis atraem mais pessoas para a economia, oferecem mais empregos, trabalhos de melhor qualidade e mais bem remunerados.

Quando analisados os relatos dos docentes, observou-se que muitos abordaram, em suas práticas pedagógicas, as temáticas de reciclagem, reutilização e reaproveitamento. Segundo o excerto da docente P1, pode-se entender que ela aborda assuntos sobre a produção de plástico biodegradável e sobre a utilização óleo de cozinha para a produção de detergentes. A docente 
P8, por outro lado, incentiva o reaproveitamento de embalagens. Os assuntos abordados pelas docentes P4 e P7 retratam a necessidade de preservar o planeta Terra em virtudes das mudanças climáticas, que ocorrem e advém das ações humanas, e dos modos de produção da sociedade. Já P9 relata que: “Trabalhamos com o tema meio ambiente e reciclagem” (P9).

Cabe ressaltar dois projetos que vêm sendo desenvolvidos na escola e que se relacionam aos ODS citados anteriormente. Silva et al. (2019) relatam que os projetos socioambientais são pensados como parte integrante das práticas pedagógicas desenvolvidas no contexto escolar. Dessa forma, inseridos nesse contexto, os projetos são desenvolvidos de forma interdisciplinar juntamente à comunidade escolar. Um desses projetos, "Papai Noel no Boi Morto", existe há muitos anos, sendo que partiu de uma iniciativa pessoal de uma das docentes, que, com o apoio de familiares e amigos, utiliza um maquinário agrícola para distribuir brinquedos e alimentos para as crianças. Ao longo dos anos, muitos escolares residentes da comunidade foram contemplados com esse projeto. Tal participação os influenciou a auxiliar e contribuir para a arrecadação de donativos, para que outras crianças fossem contempladas. Assim, no ano de 2019, a comunidade escolar deu início a um trabalho de captação de recicláveis que são vendidos e o valor arrecadado é revertido para a compra de presentes.

Com escopo similar, o projeto "Tampinha Paratleta" é um projeto socioambiental, desenvolvido pela Associação Santa-Mariense Paradesportiva (ASSAMPAR), que tem como objetivo coletar lacres de latas e tampas plásticas para serem reciclados. Após a venda desses recicláveis, são adquiridos equipamentos adaptados voltados ao paradesporto. No referido contexto escolar, ambos os projetos foram inseridos com o objetivo de conscientizar a comunidade escolar sobre a importância de separar e reciclar o lixo, além de refletir sobre a inclusão social e as relações de consumo embutidas no contexto atual da sociedade. Também estimulam nos escolares a reflexão de que eles, mesmo como crianças, são parte integrante da sociedade e responsáveis pelo meio em que vivem. Destarte, os docentes envolvidos perceberam uma ampla participação dos estudantes e familiares na arrecadação dos recicláveis, o que enfatiza a importância do envolvimento dos estudantes nos processos formativos, bem como a realização de projetos interdisciplinares como ferramenta para a melhoria do ensino e para o desenvolvimento da educação socioambiental (SILVA et al., 2019).

Nesse sentido, tais trabalhos pedagógicos podem ser assimilados aos ODS 11 - Tornar as cidades e os assentamentos humanos inclusivos, seguros, resilientes e sustentáveis -, ODS 12 - Assegurar padrões de produção e de consumo sustentáveis_ e ao Projeto Político 
Pedagógico da Escola (PPP), o qual ressalta: “[...] espera-se desenvolver uma sociedade mais democrática, limpa, sustentável e propor soluções conjuntas para os diversos problemas urbanos que vivenciamos cotidianamente e, também, colocar o aluno como protagonista e agente transformador da sociedade em que vive" (PPP, 2018, p. 7).

Sendo assim, é possível perceber a necessidade de estudos e pesquisas relacionadas ao meio ambiente. $\mathrm{O}$ uso consciente e a preservação do espaço ambiental são ponto importante em sala de aula, como meio de compartilhar conhecimentos referentes ao ambiente, a aquisição de visões de mundo que possibilitem o respeito a todas as formas de vida e o entendimento de que a existência só se dá pelas complexas teias tecidas pelos elementos naturais e socioculturais. (LISBOA; KINDEL, 2012).

As análises das discussões desencadeadas após o processo formativo permitiram constatar que as ações acima descritas foram desenvolvidas juntamente com a comunidade escolar, em formato de projetos, informações fornecidas e como meio de auxiliar a comunidade a tornar-se mais sustentável. Nesse sentido, pode-se perceber associações entre os relatos e os ODS 17. Assim, as comunidades podem buscar parceiros, compartilhar ideias e promover uma forma mais sustentável nas escolhas corretas para a vida.

Nessa perspectiva, ressalta-se um estudo realizado por Candito et al (2020) na qual as autoras procuram através de reflexões e discussões, sinalizar para problemática do planeta na atualidade, as relações entre os sujeitos e estratégias para que a educação promova os ODS, articulado à educação CTS, na urgência de tornar possível a participação cidadã na busca e implementação de soluções para a transição para uma sociedade mais sustentável. A investigação propôs ações aos docentes de uma escola pública estadual, articular a tríade CTS, as temáticas consideradas relevantes pelos professores, numa perspectiva que envolvessem os aspectos científicos, tecnológicos e sociais. Conforme citado pelas autoras, por meio da formação os professores foram oportunizados a uma integração de diferentes ações, que tinha como finalidade viabilizar um momento dialógico por meio da abordagem CTS, em complemento com a proposta dos ODS no ambiente escolar, e mediando esse conhecimento aos escolares, para a melhoria do ensino-aprendizagem. Em complemento, as autoras, acreditam que a formação docente é essencial para que um dos mais importantes documentos que pensam o desenvolvimento sustentável, a Agenda 2030, chegue até a escola e que os educandos possam ser multiplicadores desses saberes em suas casas e comunidades (CANDITO et al., 2020). 
Além do mais, ressalta-se que as ações desenvolvidas pelos professores e pela intuição escolar corroboram com o Projeto Político Pedagógico da Escola, pois a temática:

Construindo cidadania viveremos em paz' será desenvolvida ao longo do ano letivo e objetiva vivenciar, conhecer e discutir o que é cidadania, o que são deveres e direitos e quais atitudes e ou ações que cabe a cada aluno e cidadão, e que são imprescindíveis para tornar a vida de cada um melhor e, como consequência, uma sociedade de convivência pacífica e feliz. (PPP, 2018, p. 7).

De tal modo, a escola é um espaço colaborativo na construção da cidadania, onde se possibilita aprender valores. A partir desse pressuposto, as escolas da educação básica podem discutir as questões ambientais e luz da perspectiva CTS, pois a partir de práticas pedagógicas em sala de aula, é possível desenvolver diversos conhecimentos, que permitem uma visão das questões sociocientíficas, tecnológicas e ambientais, enfatizando primeiramente, o local seguido do global (SANCHES e MOREIRA, 2017). Os autores ainda frisam que o processo de ensino e aprendizagem voltado para as questões ambientais pode apresentar um papel significativo na comunidade, mediante a criação de espaços que possibilitem a discussão e a reflexão dos cidadãos integrantes de um processo formativo preparados para colaborar com a construção de uma sociedade mais justa e saudável.

Ao observar a BNCC, entende-se que os objetivos da educação estão relacionados com a transformação da sociedade, com as relações humanas e com a sustentabilidade (BRASIL, 2017). Diante disso, se relacionam com os ODS, uma vez que consistem na inter-relação sustentável entre o desenvolvimento humano e a natureza, sendo o homem parte desse ambiente. Já os Temas Transversais expressam conceitos e valores básicos à democracia e à cidadania, além de obedecerem a questões importantes e urgentes para a sociedade contemporânea. A ética, o meio ambiente, a saúde, o trabalho e o consumo, a orientação sexual e a pluralidade cultural não são disciplinas autônomas, mas temas transversais, constituídos pelos Parâmetros Curriculares Nacionais (PCN's) que devem permear todas as áreas do conhecimento, e expressam conceitos e valores básicos à democracia e à cidadania e obedecem a questões importantes e urgentes para a sociedade contemporânea (BRASIL, 1998). Nesse sentido, a BNCC discorre acerca de uma política educacional que atende aos ODS e que pode ser representada nas práticas docentes, posto que se constitui como auxílio necessário para alcançar um ensino de qualidade e representativo. Ao analisar os ODS abordados pelos professores, verifica-se que estão em consonância com o documento basilar que atende à área da educação. 
Em um estudo realizado por Ramineli e Araújo (2019), ressalta-se que é preciso um ambiente de aprendizagem/escolar preparado para fornecer uma prática formativa que leve o sujeito a se ver inserido nas problemáticas apresentadas pelos ODS. É essencial que esse espaço educativo garanta muito mais do que apenas transmissão de informação. Logo, torna-se fundamental que as instituições escolares estejam preparadas para promover práticas e experiências formativas que levem os sujeitos a se verem inseridos nas problemáticas apresentadas pela sociedade no mundo contemporâneo.

O Relatório Final da Avaliação da Década da Educação para o Desenvolvimento Sustentável (UNESCO, 2005) sugere que sejam elaborados cursos para formação de professores a fim de que se preparem para tornar-se mediadores no processo de ensino interdisciplinar para a sustentabilidade e compreender os princípios básicos do desenvolvimento sustentável. Torna-se importante que os professores se sintam encorajados a repensar a sua prática pedagógica e passem a cooperar com a disseminação de propostas em vista do desenvolvimento sustentável.

Para isso, é importante realizar uma revisão nos conteúdos curriculares, desde a Educação Infantil até o Ensino Superior, com a intenção de desenvolver um entendimento interdisciplinar de sustentabilidade social, econômica e cultural. Existe uma urgência em formar estudantes, pautando-se na alfabetização científica, que sejam capazes de compreender os problemas mundiais, discuti-los e propor soluções (PRAIA; GIL-PÉREZ; VILCHES, 2007). Logo, observa-se que as relações existentes entre os conhecimentos científicos e o cotidiano são indicadas como umas das formas de aperfeiçoar os processos de ensino e de aprendizagem. Nesse sentido, o professor passa a exercer um papel importante nos debates que procuram compreender a sensibilização dos estudantes para a consciência sustentável.

Fazenda (2008) destaca a importância da formação interdisciplinar para integração de saberes, na busca por não se limitar ao reducionismo disciplinar. Nesse sentido, Rossi et al. (2013) ressaltam que, por meio da interdisciplinaridade a escola proporciona um complemento no conhecimento escolar, já que ocorre a partir da interação de duas ou mais disciplinas na troca de saberes e no compartilhamento de ideias. Compreende-se, assim, a interdisciplinaridade como uma ferramenta indispensável para a construção de novos saberes, que enobrece as trocas de vivências e de conhecimentos. Fazenda (2008) cita que a interdisciplinaridade escolar favorece as noções, finalidades, habilidades, técnicas e, sobretudo, o processo de aprendizagem, respeitando os saberes dos estudantes e sua integração com os saberes científicos. 
Nesse contexto, as práticas pedagógicas desenvolvidas por meio da interdisciplinaridade favorecem os processos participativos que norteiam as discussões e ações prioritárias dentro da escola e da comunidade. Com isso, por meio dos ODS fortalecem-se os projetos pedagógicos, posto que, a partir de situações do cotidiano do estudante auxiliam na formação de jovens críticos, responsáveis e autônomos, que compreendem a complexidade dos impactos de suas ações e seu potencial de colaboração para a construção de uma sociedade mais justa e sustentável.

\section{CONSIDERAÇÕES FINAIS}

Desde a década de 1960, quando o meio ambiente passou a ser alvo de discussões fervorosas como um bem global e finito do qual o próprio homem faz parte, até os dias atuais, a luta para que se tenha um meio ambiente ecologicamente equilibrado continua, de forma cada vez mais intensa. A busca por alcançar os ODS por meio da educação é encarada como possibilidade de combate à degradação ambiental. Assim, trata-se de uma estratégia de mudança, de acordo global sobre a forma de tratar o meio ambiente; é um processo que vislumbra educar de forma prática, para que a sociedade evolua e cuide do meio ambiente do qual faz parte.

A formação docente para uma educação mais crítica, que possibilite o empoderamento dos estudantes críticos, reflexivos e sustentáveis, integra os esforços para o alcance dos ODS. Desse modo, formações continuadas desenvolvidas com docentes por meio a educação CTS articulada aos ODS, apontam caminhos para uma educação que envolva os professores em uma nova forma de ver, pensar, e desenvolver suas práticas, para uma formação de seus escolares como indivíduos responsáveis, capazes de decidir e agir num processo de mudança, e com um pensamento orientado para o futuro (CANDITO et al. 2020).

Esse estudo se soma a um contexto de trabalho colaborativo entre a escola e pesquisadoras da Universidade Federal de Santa Maria-RS, com vistas à melhoria dos processos de ensino e de aprendizagem, contribuindo para a evolução de práticas pedagógicas e para a promoção e/ou alcance dos ODS na perspectiva da inserção e articulação entre os ODS e CTS nas práticas docentes. Não obstante, os ODS articulados à educação CTS ampliam a possibilidade de trabalhar com uma proposta integradora do currículo escolar, possibilitando aos estudantes a percepção do contexto global, amplo e responsável em que se inserem.

Dessa forma, acredita-se que, ao promover mudanças nas ações e no comportamento dos cidadãos, bem como no funcionamento das sociedades, a partir do importante papel que a 
educação científica desempenha, será possível preparar os sujeitos à participação cidadã na busca e implementação de soluções para a transição das sociedades atuais para sociedades sustentáveis.

Faz-se necessário enfatizar que estudos semelhantes a este, por meio do qual buscou-se a promoção e articulação entre os ODS e CTS em um processo de formação continuada, são incipientes na literatura. Tal fator demonstra a necessidade da realização de propostas como essa no ambiente escolar, e torna esse estudo um diferencial no campo de formação de professores e práticas pedagógicas, destacando-se como um potente referencial. Ademais, espera-se contribuir com o avanço de estudos na formação docente e sua integração em salas de aulas.

\section{REFERÊNCIAS}

BARDIN, Laurence. Análise de conteúdo. 1. ed. São Paulo: Edições 70, 2016.

BAZZO, Walter; COLOMBO, Ciliana. Educação tecnológica contextualizada: ferramenta essencial para o desenvolvimento social brasileiro. Revista de Ensino de Engenharia, Florianópolis, v. 20, n. 1, p. 9-16, 2001. Disponível em: https://docplayer.com.br/42566866Educacao-tecnologica-contextualizada-ferramenta-essencial-para-o-desenvolvimento-socialbrasileiro.html. Acesso em:10 mar. 2021.

BRASIL. Parâmetros curriculares nacionais: terceiro e quarto ciclos: apresentação dos temas transversais. Brasília: MEC/SEF, 1998.

BRASIL. Base Nacional Comum Curricular. Brasília, DF: Ministério da Educação, 2017.

BIGLIARDI, Rossane Vinhas; CRUZ, Ricardo Guatério. O papel da educação ambiental frente à crise civilizatória atual. Ambiente \& Educação, Rio Grande do Sul, v. 12, p.127141, 2007. Disponível em: https://periodicos.furg.br/ambeduc/article/view/810. Acesso em: 08 mar. 2021.

CANDITO, Vanessa et al. Os objetivos de desenvolvimento sustentável articulados à abordagem CTS na formação de professores. In: Encontro sobre Investigação na Escola, 16., 2020, Santo Antônio da Patrulha. Anais [...]. Santo Antônio da Patrulha: FURG, 2020.

FAZENDA, Ivani Catarina Arantes. Interdisciplinaridade: História, Teoria e Pesquisa. 15 . ed. Campinas: Papirus, 2008.

FREIRE, Paulo. Pedagogia da Autonomia: saberes necessários à prática educativa. $41^{\mathrm{a}}$. ed. São Paulo: Paz e Terra, 2010.

GIL, Antônio Carlos. Como elaborar projetos de pesquisa. 4. ed. São Paulo: Atlas, 2008.

LISBOA, Cassiano Plamplona; KINDEL, Eunice Aita Isaia. Educação Ambiental da teoria à prática. Porto Alegre: Editora Mediação, 2012. 
MENEZES, Karla Mendonça et al. Educação em saúde no contexto escolar: construção de uma proposta interdisciplinar de ensino-aprendizagem baseada em projetos. Rev. Ed. Popular, Uberlândia, Edição Especial, p. 48 -66, jul. 2020.

MOHR, Adriana. A natureza da educação em saúde no ensino fundamental e os professores e os professores de ciências. 2002. 410 f. Florianópolis: Tese (Pós-Graduação em Educação) - Universidade Federal de Santa Catarina, Florianópolis, 2002. Disponível em: https://repositorio.ufsc.br/xmlui/handle/123456789/83375. Acesso em: 23 fev. 2021.

NÓVOA, Antonio. Professores: Imagens do futuro presente. Lisboa: Educa, 2009.

ONU. Objetivos de Desenvolvimento Sustentável (ODS). 2017. Disponível em: https://nacoesunidas.org/pos2015/. Acesso em: 30 jan. 2021.

PINHEIRO, Nilcéia Aparecida Maciel. Educação Crítico-Reflexiva para um Ensino Médio Científico -Tecnológico: a contribuição do enfoque CTS para o ensino-aprendizagem do conhecimento matemático. 2005. 306 f. Tese (Pós-Graduação em Educação Científica e Tecnológica) - Universidade Federal de Santa Catarina, Florianópolis, 2005. Disponível em: https://repositorio.ufsc.br/handle/123456789/101921. Acesso em: 23 fev. 2021.

PPP - PROJETO POLÍTICO PEDAGÓGICO. Escola Estadual de Ensino Médio Marechal Humberto de Alencar Castelo Branco. Santa Maria: EEEM Marechal Humberto de Alencar Castelo Branco, 2018.

PRAIA, João; GIL-PÉREZ, Daniel; VILCHES, Amparo. O papel da natureza da ciência na educação para a cidadania. Ciência \& Educação, Bauru, v. 13, n. 2, p. 141-156, 2007. https://doi.org/10.1590/S1516-73132007000200001.

RAMINELI, Jorge Luiz Ferreira; ARAUJO, Magnólia Fernandes Florêncio de. Os Objetivos de Desenvolvimento Sustentável (ODS) sob o olhar da práxis Freiriana. In: ENCONTRO NACIONAL DE PESQUISA EM EDUCAÇÃO EM CIÊNCIAS, 12., 2019, Natal. Anais [...]. Natal: UFRN, 2019. Disponível em: https://abrapecnet.org.br/enpec/xiienpec/anais/resumos/1/R2009-1.pdf. Acesso em: 23 jan. 2021.

RODRÍGUEZ, Andrei Steveen Moreno; DEL PINO, José Claudio. Abordagem Ciência, Tecnologia e Sociedade (CTS): perspectivas teóricas sobre educação científica e desenvolvimento na América Latina. Tear: Revista de Educação Ciência e Tecnologia, v. 6, n. 2, 2017.

RODRIGUES, Carolina Braz Carlan et al. Contribuições de uma proposta contínua de formação docente articulada por meio da relação escola-universidade. In: SAWITZKI, Rosalvo Luis; MARTINY, Luis Eugênio; JAEGER, Angelita Alice (orgs.). Vida, vivência e experiência de professores(as) de educação física. Curitiba: CRV, 2020. p.151-164.

ROSSI, Daniela Sastre et al. Imagem corporal, aspectos nutricionais e atividade física em estudantes de uma escola pública. Adolescência \& Saúde, v. 10, p. 36 44, 2013.

SANCHES, Denise Godoi Ribeiro; MOREIRA, Ana Lúcia Olivo Rosas. CTS e a educação ambiental: possibilidades nas diretrizes curriculares do ensino médio. In: CONGRESO 
INTERNACIONAL SOBRE INVESTIGACIÓN EN DIDÁCTICA DE LAS CIENCIAS, 10., 2017, Sevilla. Anais [...]. Sevilla, 2017.

SANTOS, Wildson Luiz Pereira dos; MORTIMER, Eduardo Fleury. Uma análise de pressupostos teóricos da abordagem CTS (Ciência-Tecnologia-Sociedade) no contexto da educação brasileira. Ensaio, v. 2, n. 2, p. 1-23, 2002. https://doi.org/10.1590/1983$\underline{21172000020202}$

SANTOS, Wildson Luiz Pereira dos; SCHNETZLER, Roseli Pacheco. Educação em Química: Compromisso com a cidadania. Ijuí: UNIJUÍ, 2015.

SILVA, Fatima Goreti Vilanova da et al. A reciclagem solidária como ferramenta para educação socioambiental. In: JORNADA ACADEMICA INTEGRADA, 34., 2019, Santa Maria. Anais [...]. Santa Maria: UFSM, 2019.

SOUZA, Nely Soraya Bahia; ALMEIDA, Ana Cristina Pimentel Carneiro de. Ensino de Ciências: O Enfoque CTS e a Ilha Interdisciplinar de Racionalidade (IIR). Revista Brasileira de Ensino de Ciência e Tecnologia, Ponta Grossa, v.13, n. 3, p. 150-167, set./dez. 2020.

UNESCO. Década da Educação das Nações Unidas para um Desenvolvimento

Sustentável, 2005-2014: documento final do esquema internacional de implementação. Brasília: UNESCO, 2005.

UNESCO. Educação para os Objetivos de Desenvolvimento Sustentável: objetivos de aprendizagem. São Paulo: UNESCO, 2017.

ZEICHNER, Kenneth. Uma análise crítica sobre a "reflexão" como conceito estruturante na formação docente. Educação \& Sociedade, Campinas, v. 29, n. 103, p. 535-554, maio/ago. 2008. Disponível em: https://www.scielo.br/pdf/es/v29n103/12.pdf. Acesso em: 08 fev. 2021. 